\title{
Biblioteca de componentes digitais para gestão pública participativa
}

\author{
Library of components for participatory public management
}

\author{
Eunice Liu, Keiko Ono Verônica Fonseca, Lukas Wesley Cascione
}

governança pública, colaboratividade, processos participativos, democracia eletrônica, features

\begin{abstract}
Este trabalho busca contribuir com uma biblioteca de componentes digitais, pesquisados por meio de aplicativos, para propulsionar processos participativos online, visando a construção e manutenção de democracias, com protagonismo de todas as partes interessadas da sociedade, para legitimação de decisões políticas em governança pública. Dados fornecidos por tais componentes servem para promover o exercício da cidadania no monitoramento das cidades, detecção de problemas e situações de risco, fiscalização, proposição e implementação de soluções, manutenção de ordem pública e diálogo entre grupos de interesse, organização civil, iniciativa privada e autoridades públicas, para melhoria e desenvolvimento do ambiente urbano. Prezam por ampliar as formas de contato, de modo a subsidiar elaboração de políticas públicas, reduzindo barreiras de acessibilidade e suportando os princípios de respeito aos direitos fundamentais do homem e de sua autonomia e para o bem comum.
\end{abstract}

public governance, collaboration, participatory processes, electronic democracy, features

This work aims to contribute with a library of components, researched through applications, to propel online participatory processes, for the construction and maintenance of democracies, with the protagonism of all stakeholders of society, to legitimate political decisions in public governance. Data provided by such components serve to promote the exercise of citizenship in the monitoring of cities, detecting problems and risky situations, inspecioning, proposing and implementing solutions, for the maintenance of public order and dialogue between interest groups, civil organization, private initiative and public authorities, to the improvement and development of the urban environment. They value expanding forms of contact, in order to subsidize the elaboration of public policies, reducing barriers of accessibility and supporting the principles of respect for the fundamental rights of man and his autonomy and for the common good.

\section{Introdução}

Processos participativos são chaves na construção e manutenção de democracias, são uma série de processos, instrumentos, ferramentas e práticas que visam participação de todas as partes envolvidas em um projeto desde sua concepção. O design participativo envolve a participação do usuário no design para a prática de trabalho. O design participativo é um processo democrático para o design (social e tecnologicamente) de sistemas que envolvem trabalho humano, com base no argumento de que os usuários devem estar envolvidos nos 
designs que farão uso, e que todas as partes interessadas, incluindo e especialmente os usuários, têm igual contribuição na interação do design (Muller \& Kuhn, 1993).

A participação cidadã é, por sua vez, a possibilidade de que todos, especialmente as minorias, participem da determinação de objetivos, políticas, leis, recursos, compartilhamento de informações e programas da esfera pública. Por mais que a definição seja simples, a questão é bem mais complexa do que o simples acesso de cidadãos à participação política ativa, havendo fatores contextuais envolvidos que atuam como barreiras à esta participação (Arstein, 1969; Organisation for Economic Co-operation and Development [OECD], 2001). Ou seja, "forças dinâmicas de tipo social, cultural, econômico, político, tecnológico e institucional exercidas localmente pelos atores locais e pelo contexto ao qual pertencem". (Edward \& Steins, 1999, as cited in Gaudio, 2019, p. 27).

Esses processos têm sua efetividade crescente com a expansão de ferramentas digitais de coleta de dados por engajamento cidadão, em largo volume, conhecendo suas vontades, opiniões, proposições, assim como suas insatisfações e queixas, oportunizando o rompimento de algumas destas barreiras ao se operadas em conjunto com os demais fatores contextuais.

A Lei no 14.129, sancionada no Brasil em Março de 2021, "dispõe sobre princípios, regras e instrumentos para o aumento da eficiência da administração pública, especialmente por meio da desburocratização, da inovação, da transformação digital e da participação do cidadão." (Lei $n^{\circ}$ 14.129, 2021), e propõe, dentre diversas coisas, o uso de assinaturas eletrônicas, e a unificação de bancos de dados governamentais, facilitando e possibilitando o aumento potencial de comunicação entre órgãos públicos e cidadãos, afirmando preservar a privacidade dos dados pessoais das pessoas de acordo com a Lei Geral de Proteção de Dados Pessoais.

A ciência dos dados advindos da população cidadã, processados em escala, podem fomentar a elaboração de políticas públicas justas e igualitárias, benéficas à sociedade civil em $\mathrm{si}$, assim como às comunidades em que estão inseridos, às cidades e aos contextos regionais e global, quando bem articulados e eticamente processados.

Este trabalho busca contribuir com uma biblioteca de componentes digitais para propulsionar processos participativos online, em termos de experiência e interface. Não é escopo deste artigo delimitar o nível de engajamento comunitário por meio dos componentes, em cada um dos conceitos teóricos apresentados, ou propor uma solução definitiva para a participação cidadã pautada somente na melhoria ou ampliação de soluções digitais.

\section{Justificativa}

A Constituição Federal do Brasil, de 1988, foi exemplo de processo democrático de gestão pública brasileira, com participação cidadã efetiva na elaboração de projetos, gerando projetos de lei e emendas parlamentares - algumas das quais perduram até hoje - no âmbito federal, estadual e municipal, redigida conjuntamente com cidadãos, escrevendo e enviando cartas com suas propostas, de todo o país. O: 
Estado Democrático de Direito conforme definido em sua Constituição, o Brasil estabelece duas vias de participação democrática da população nas escolhas que definem os rumos do país: indireta e direta. Na democracia indireta, o povo elege representantes [...]. A democracia direta, por sua vez, pressupõe a participação efetiva do povo. Cada cidadão terá voz e poder de decisão sobre determinado assunto. O texto da Constituição Federativa de 1988 prevê três mecanismos de participação direta do povo: Plebiscito; Referendo; Iniciativa Popular (Brasil, 2018).

Outro exemplo governamental atual que visa ampliar a participação cidadã é a OuvidoriaGeral, do Ministério das Cidades, criado em 2003, cujo nome foi modificado, em 2019, em conjunção com o Ministério da Integração Nacional, para Ministério do Desenvolvimento Regional. Sendo este um canal para receber denúncias, solicitações, sugestões, reclamações, elogios e pedidos de informação relativos às políticas e às ações da Pasta (Ministério do Desenvolvimento Regional [MDR], 2020). Este ministério que tem como objetivo promover o desenvolvimento das cidades, também prevê participação social, por meio de programas nacionais como o 'Capacidades', que aponta como um de seus objetivos "VII - estimular a ampla participação dos agentes públicos e sociais" além de pontuar a importância da gestão democrática da cidade (Capacidades, n.d.), e o 'Dialoga Brasil', como um espaço web para apresentação de ideias cidadãs (Dialoga Brasil, n.d.).

Esses canais demonstram a importância para a gestão pública de compreender aquele para quem se governa, a coletividade. Com o intuito de ampliar, facilitar e promover ativamente processos participativos cidadãos, para mais efetiva coleta de dados que possam contribuir com agentes governamentais e organizações interessadas, na elaboração de políticas pública efetivas, esta pesquisa se destinou a investigar e elencar uma biblioteca de de componentes digitais que possam potencializar o entendimento da voz cidadã, para por meio delas entender demandas do contexto urbano, local, comunitário, para melhor governança de sua população e seus espaços comuns habitáveis.

\section{Desenvolvimento}

Neste trabalho optou-se por avaliar somente componentes do ambiente digital considerando os dados da pesquisa feita pelo IBGE em 2019 sobre inclusão digital, que afirma que $78 \%$ da população possui acesso à internet, chegando o percentual de acesso na área urbana a 91,9\%, sendo menor na área rural. Embora o acesso na área rural seja menor e ainda haja 40 milhões de pessoas excluídas do ambiente digital, têm-se conhecimento de que os processos participativos devem incluí-las por meio de mecanismos externos ao ambiente digital - para fidedignidade de cenário -, alguns dos quais estão elencados na Figura 1, abaixo (Instituto Brasileiro de Geografia e Estatística [IBGE], 2021). 
Figura 1: Mecanismos de participação popular offline

caixa postal | central telefônica | orçamento participativo

fórum | conselho | conferência | audiência pública | workshop | oficina | hackathon formulário | consulta em praça/espaço público entrevista | audiência | workshop votação | plebiscito | referendum | co-design | escritório de projeto aberto ao público

Os processos participativos digitais variam entre modalidades de participação menos e mais ativas, indo de contribuição cidadã fornecendo dados e informações pessoais sobre assuntos diversos à apresentação de propostas e meios de implementação de soluções, nestes últimos com contribuições dos cidadãos e organizações da sociedade civil, participando em processos governamentais decisórios.

Para o levantamento de componentes digitais, objetos desta pesquisa, determinou-se palavras-chave - a partir de conceitos, definições, termos sinônimos e afins - relacionadas ao tema, resultando em um total de 24 termos, elencados na Tabela 1, sendo estes, tanto em língua portuguesa quanto em língua inglesa.

Tabela 1: Lista de Palavras-Chave da Pesquisa

\begin{tabular}{|c|c|}
\hline Idioma & Palavras-Chave \\
\hline Português & $\begin{array}{l}\text { Boa Governança; Colaboratividade; Co-design; Processos participativos; Democracia } \\
\text { Eletrônica; Governança Democrática; Governança Digital; Governança em Rede; } \\
\text { Governança Pública; Governo Digital; Interface Socioestatal; Orçamento Participativo; } \\
\text { Participação Cidadã; Participação Pública; Processos Participativos; Rede de } \\
\text { Governança; Rede Social para a Cidadania; }\end{array}$ \\
\hline Inglês & $\begin{array}{l}\text { App Governance; Citizen Participation; Citizen Poll; Civic Engagement; Colab; } \\
\text { Collaborative Governance; E-Governance; Public Participation; Public Policy; }\end{array}$ \\
\hline
\end{tabular}

Por meio das palavras-chave listadas realizou-se a busca de aplicativos prioritariamente mobile - principal canal de acesso atual à internet (IBGE, 2021) - e disponíveis na Play Store, atual maior loja de aplicativos da plataforma Android, que em etapa posterior da pesquisa foram filtrados. Concomitante à pesquisa de apps foram listadas as features, ou seja, características e funcionalidades de uso do sistema, observadas nos aplicativos, cuja finalidade fosse contribuir, viabilizar e facilitar a participação cidadã ou servir a estes cidadãos de alguma maneira, ligadas ao benefício alcançado pelo usuário.

Os aplicativos encontrados foram catalogados com as seguintes informações: nome, categoria, publisher, provedor público ou privado, esfera de atuação do provedor, features, número de downloads e data de publicação/última atualização. O levantamento foi realizado entre 09 de fevereiro e 09 de março de 2021 e identificou ao todo 158 apps de utilidade pública, de desenvolvedores públicos ou privados, variando entre apps de governança digital, com participação passiva e indireta do cidadão, isto é, para acesso a informações de consulta, 
serviços ou consultas de informações pessoais, à apps de participação cidadã mais ativa e direta, com processos de proposição, discussão e eleição de ações da autoridade local. A lista dos aplicativos levantados pode ser acessada no QR code disponibilizado na Figura 2.

Figura 2: Apps Cidadãos

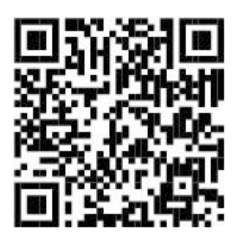

A classificação para análise posterior, focou nos aplicativos em que a participação ocorria de forma ativa. Neste sentido, aplicativos de serviços públicos disponíveis para cidadãos e de ouvidoria (ex.: SP Serviços e apps do Gov.br), caracterizados por uma participação menos ativa, apesar de serem importantes bases de dados para entendimento do panorama das cidades e regiões do país, não foram considerados.

Da lista geral de aplicativos, 13 apps foram então priorizados, catalogados e analisados a partir de imagens de interface dos aplicativos, disponibilizadas na loja, sua descrição, download de sua versão completa ou web, para conhecimento e listagem de features de participação cidadã, como: criação de comunidades, consulta pública, canal de conversa, denúncia, decisões de grupo, discussão, fiscalização, informações, serviços digitais, sugestões e votação digital, conforme apresenta a Tabela 2.

Tabela 2: Aplicativos Priorizados

\begin{tabular}{lll}
\hline $\begin{array}{l}\text { Nome do App } \\
\text { (País/Ano) }\end{array}$ & Palavra-Chave & Features \\
\hline $\begin{array}{l}\text { Cidadão Mais Brasil } \\
\text { (Brasil/2018) }\end{array}$ & Citizen Participation; Governo Digital; & $\begin{array}{l}\text { Comunidade; Consulta; Denúncia; } \\
\text { Fiscalização; Informações; }\end{array}$ \\
\hline $\begin{array}{l}\text { Colab } \\
\text { (Brasil/2013) }\end{array}$ & $\begin{array}{l}\text { Citizen Participation; Colab; } \\
\text { Colaboratividade; Public Participation; } \\
\text { Rede Social para a Cidadania; }\end{array}$ & $\begin{array}{l}\text { Comunidade; Decisões de Grupo; } \\
\text { Denúncia; Sugestões; }\end{array}$ \\
\hline $\begin{array}{l}\text { Curitiba 156 } \\
\text { (Brasil/2019) }\end{array}$ & $\begin{array}{ll}\text { Denúncia; Fiscalização; Serviços } \\
\text { Digitais; Sugestões; }\end{array}$ \\
\hline $\begin{array}{l}\text { Curitiba App } \\
\text { (Brasil/2019) }\end{array}$ & E-Governance; & \begin{tabular}{l} 
Informações; Serviços Digitais; \\
\hline $\begin{array}{l}\text { Gobierno Abierto } \\
\text { Bogotá (Colômbia/2018) }\end{array}$
\end{tabular} \\
\hline
\end{tabular}


Loomio

(Nova Zelândia/2014)
Comunidade; Decisões de Grupo; Discussão; Sugestões; Votação Digital;

Blog; Comunidade; Decisões de

MyGov

(Índia/2015)

App Governance; Citizen Participation;

Democracia Eletrônica; E-Governance;

Public Participation; Public Policy;

Grupo; Discussão; Votação

Digital;

NationBuilder
(Estados Unidos/2009)

Governança Pública;

Blog; Comunidade; Consulta; Informações;

Ods Research \& Action

Colaboratividade;

(Panamá/2020)

Public Policy;

Comunidade; Decisões de Grupo; Discussão; Informações;

Comunidade; Decisões de Grupo, Discussão;

(Suíça/2018)

Colab;

Denúncia; Sugestões;

Prefeitura e Você

E-Governance;

Comunidade; Serviços Digitais;

Self4Society

(Índia/2018)

YouGov

Citizen Poll;

(Reino Unido/2000)

\section{Votação Digital;}

Para um melhor detalhamento das features e com o objetivo de elencar soluções que possam ser reproduzidas e adaptadas posteriormente em novas versões de aplicativos com o mesmo foco ou em futuras versões de aplicativos, funções replicáveis foram identificadas e denominadas componentes, por serem soluções de desenvolvimento, constituídos por elementos de interface diversos, que permitem a obtenção de resultados esperados pelos usuários em relação às features.

Cada um desses componentes foi descrito e exemplificado por elementos de interação que podem ter diversas soluções de interface além das apresentadas - que visam favorecer a experiência de participação cidadã, que segundo Nielsen, pode determinar se uma ação é bem-sucedida ou falha (Nielsen, 2006), pretendendo ampliar as formas de contato, reduzir barreiras de acessibilidade, para fins de engajamento público. Os componentes identificados estão listados na Tabela 3, que pode ser consultada a seguir. 
Tabela 3:Componentes digitais participativos

$\begin{array}{lll}\text { Componente Descrição Exemplo componente } & \text { Expon }\end{array}$

$\begin{array}{ll}\text { Acompanhamento } & \text { Componente para acompanhar uma } \\ \text { (Seguir/Favoritar) } & \text { atividade, ou atividade específica, como obra, } \\ & \text { proposta ou grupo de trabalho, recebendo } \\ & \text { notificações sobre alteração de seu status, } \\ & \text { visualizando informações no mural, e com } \\ & \text { rápido acesso. Possui como componentes } \\ & \text { botão, e por vezes texto com alteração } \\ & \text { contextual indicando o número de } \\ & \text { seguidores. }\end{array}$

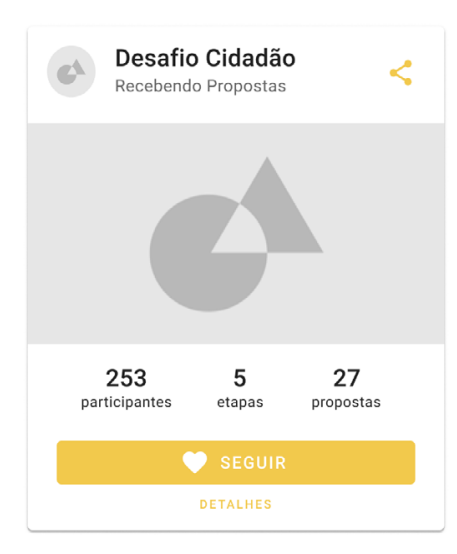

Avaliação por
Escala de Likert
(Avaliação de
Satisfação)

Avaliação por

Estrelas

Campo de Busca
(Texto/Voz)

Com o uso de uma escala de 5 ou 7 pontos, e com extremos opostos e o centro sempre neutro, é possível avaliar a satisfação dos usuários acerca de uma ação, obra, decisão, proposta, individualmente ou com múltiplos itens ao mesmo tempo. O componente pode ter sliders, ícones, texto, emojis, para facilitar seu uso.

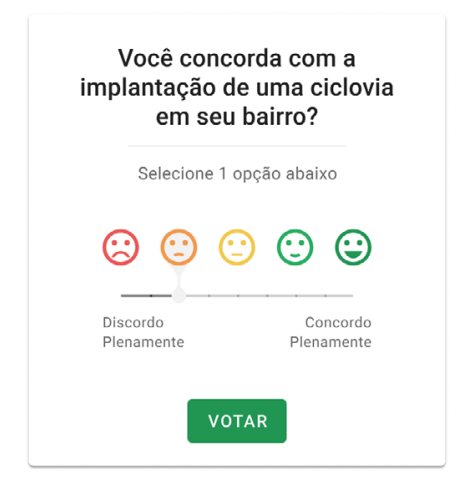

Através deste componente é possível realizar a avaliação de propostas, obras ou contratos do governo responsável, ou do próprio atendimento via aplicativo, por escala de 5 pontos, partindo sempre de 0 , utilizando estrelas, podendo às vezes possuir um intervalo não inteiro (1/2 estrelas).

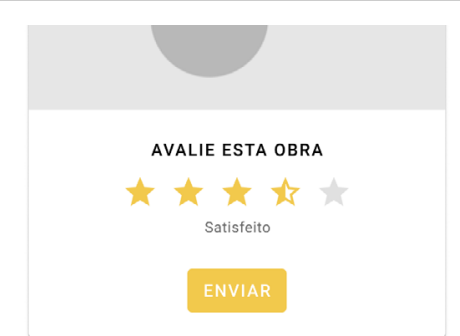

Campo constituído de caixa de texto, utilizado para realizar pesquisas textuais no aplicativo. Em algumas versões possui botão para captura de voz, permitindo realizar a busca através de comando de voz. 


\section{Chat de Atendimento (também Chatbot)}

Sistema de chat integrado à aplicação para conversar diretamente com um profissional do serviço, sanar dúvidas e questionamentos, podendo às vezes possuir um chatbot, para iniciar a conversa, ou responder dúvidas de maneira automatizada.

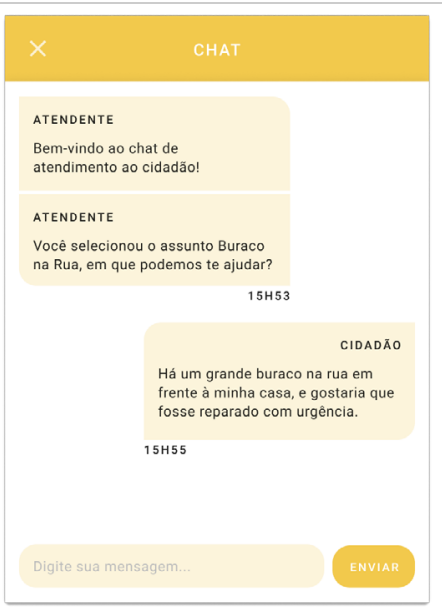

\section{Chave de}

Acesso Única
Com o uso da chave de acesso única os cidadãos podem acessar as diversas ferramentas disponibilizadas pelas autoridades públicas sem precisar criar diversos cadastros. Facilita o acesso às ferramentas, e reduz barreiras aos cidadãos. É necessário integrar bancos de dados para operar. $\times \quad$ Bem-Vindo Cidadão!

(

(ल) CHAVE ÚNICA DE ACESSO

$\leftarrow \quad$ Compartilhe esta Discussão compartilhar a atividade, grupo, desafio, informação ou protocolo.

\section{Comandos para \\ Compartilhamento \\ Externo}

\section{Consulta}

com Múltiplas

Alternativas

(Enquete)
Por meio deste componente são apresentadas alternativas, referentes a um tema, podendo-se selecionar um número máximo de escolhas. Através desse método de consulta podem ser visualizadas prioridades dentre diversas opções, eleger apenas uma alternativa ou consultar interesses.
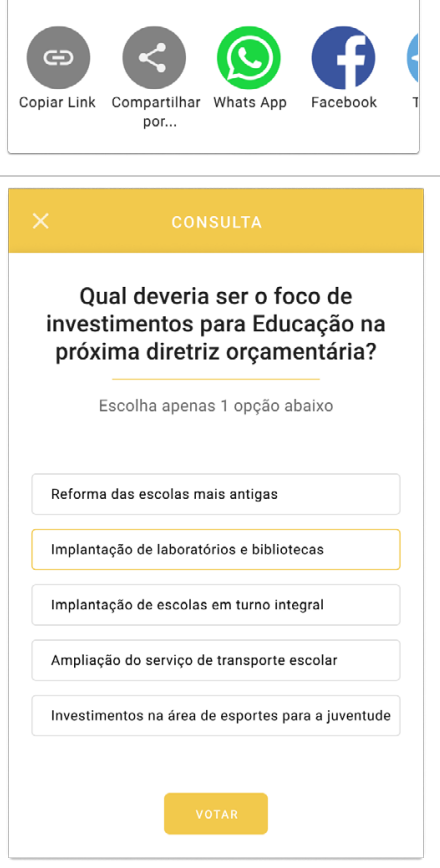
Dados em

Tempo Real
Neste componente os dados são atualizados em tempo real por meio de dados abertos do município, assim como os cedidos pelos usuários. É possível obter informações atualizadas e precisas sobre bloqueio de ruas, estações desativadas, linhas de ônibus atrasadas ou inativas, além de precisão nos dados de mobilidade, por exemplo.

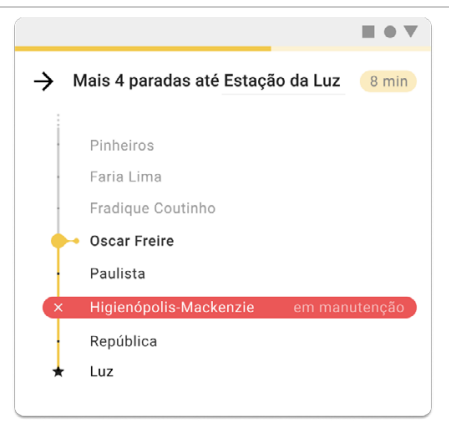

\section{Eleição Digital}

(Votação)
Por meio da inscrição no processo eleitoral e validação com documento oficial, o usuário pode participar do processo de eleição, selecionando o candidato desejado e clicando no botão votar. Os resultados da eleição são computados e apresentados no aplicativo ao término do escrutínio.

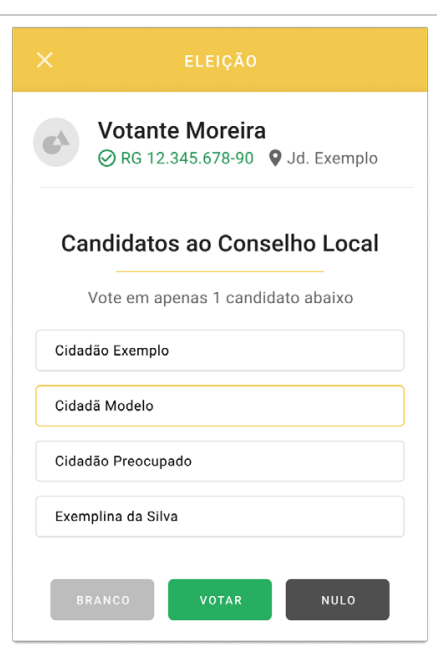

Envio de Arquivos (Imagem/Texto/Áudio / Outras Extensões)
Possibilita ao usuário anexar ou realizar o upload de arquivos de diferentes extensões diretamente no aplicativo, de forma a submeter respostas a desafios, elucidar propostas, descrever projetos, justificar votos, deixar mais claras suas denúncias ou sugestões, assim como comentar em discussões ou conteúdos no mural.
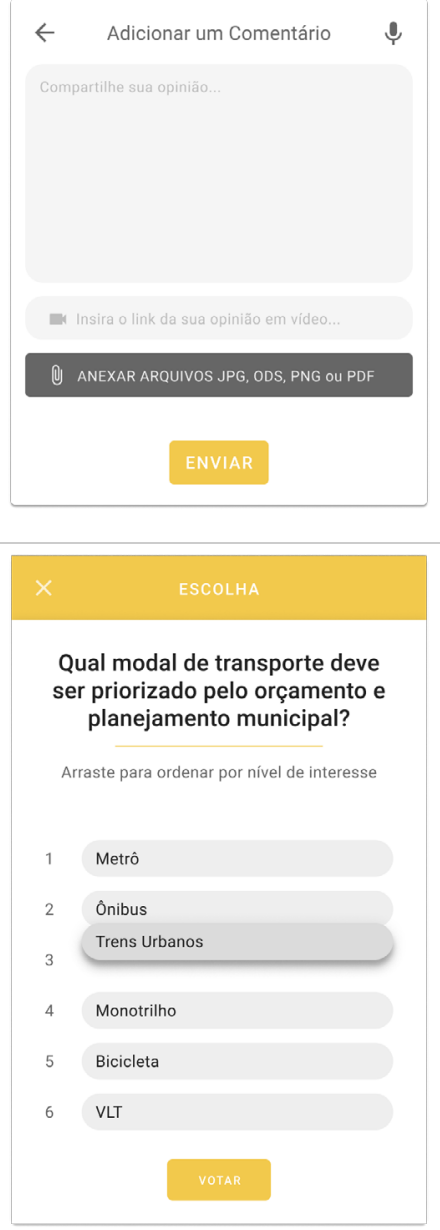

Escolha Classificada
Método de votação ou consulta que consiste em chips que devem ser ordenados do maior valor, prioridade ou interesse ao menor valor, prioridade ou interesse. Opera de forma semelhante à consulta com múltiplas alternativas, mas nesta, nenhuma alternativa é eliminada da seleção, permitindo uma visão mais ampla dos interesses dos participantes. 
Eventos

Padronizado
O componente possibilita criar, compartilhar, divulgar e inscrição em eventos específicos, assim como é organizado de forma a permitir a busca por eventos no aplicativo e a sua visualização em ordem cronológica.
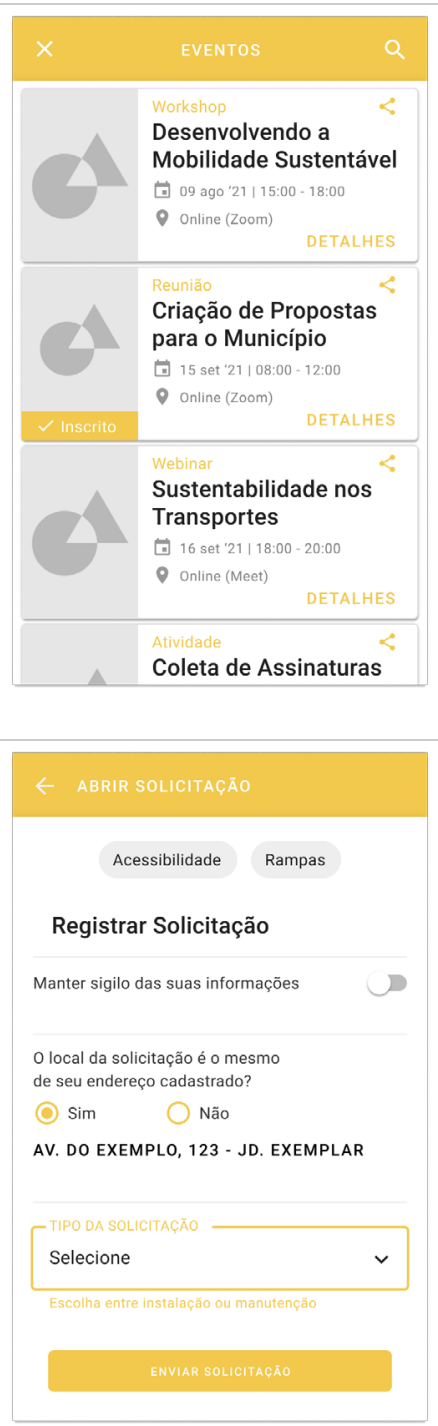

Possibilita realizar denúncia, reclamação ou sugestão (anônima ou não) se utilizando de formulários padronizados. O preenchimento é realizado através de caixas de texto, checkboxes, dropdown menus, switches, radio buttons, permitindo ao usuário apenas inserir dados conforme solicitado.
Formulário Semi-

Padronizado
Permite a realização de denúncias,

reclamações ou sugestões, por meio da seleção de uma categoria específica e de caixa de texto e envio de áudio, imagens ou vídeo, em alguns casos, para detalhar e exemplificar a solicitação. Diferentemente dos formulários padronizados, garante maior liberdade ao cidadão para compor sua solicitação e menor padronização nas respostas. Ideal para coleta de dados mais diversificada e para simplificar o processo de preenchimento do formulário.

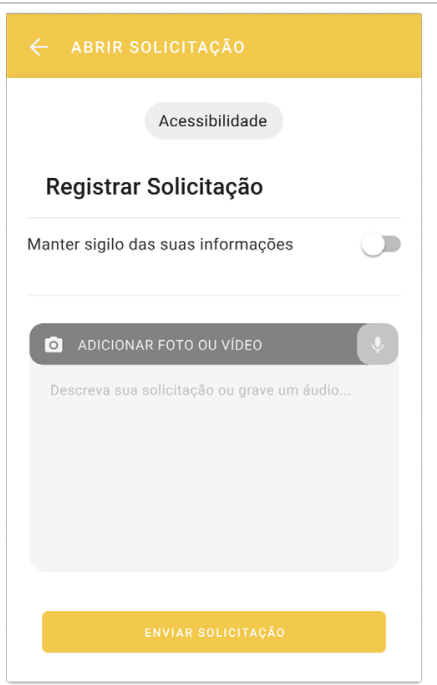


Filtro de Interesses

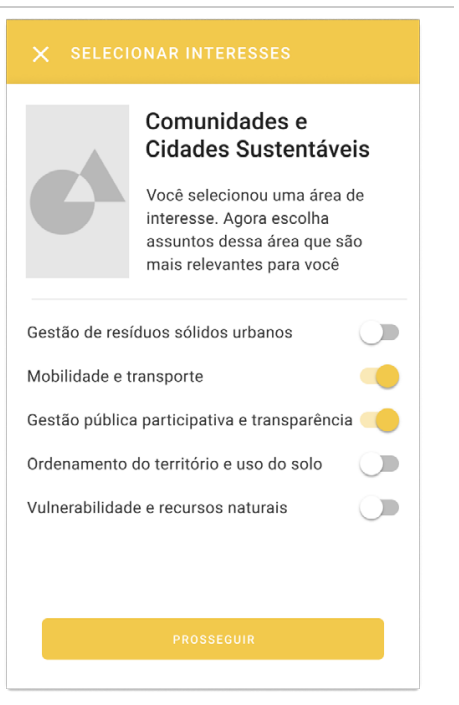

Grupos de Atividades As ações em grupo são organizadas e dispostas na forma de equipes de trabalho, que possuem de tema específico, participantes definidos, objetivos próprios e etapas de trabalho pré-definidas e prazo para conclusão. O usuário pode visualizar todos os grupos existentes, visitá-los para verificar as atividades e os participantes, e decidir participar dele, se for de seu interesse.

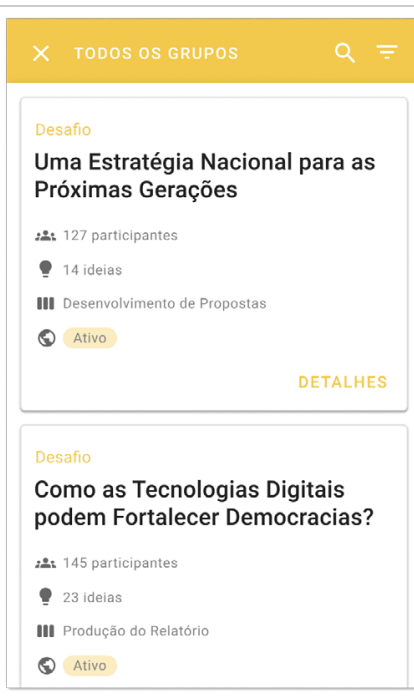

Indicação de

Classificação do

Usuário
O componente permite que os usuários sejam classificados de acordo com sua atividade no aplicativo, sendo possível monitorar seu ranking de participação e o de outros usuários. Incentiva a atividade constante dos usuários na plataforma.

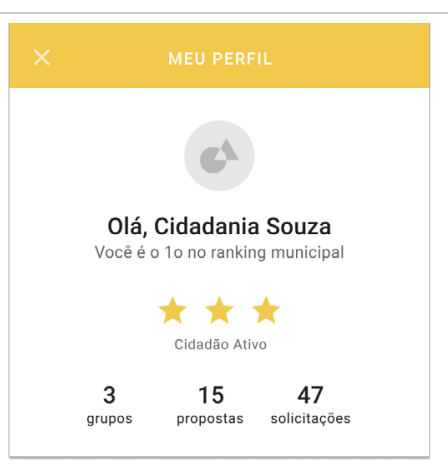


Indicador de

Progresso

\begin{abstract}
A interface do aplicativo possui uma representação visual das etapas do grupo de atividades, das etapas do processo participativo, ou ainda dos desafios ou missões, permitindo identificar as etapas já concluídas, as futuras e a atual com as tarefas a serem realizadas pelo grupo. É constituído de componentes como barra de progresso, ícones, caixas de texto, botões e informações textuais.
\end{abstract}

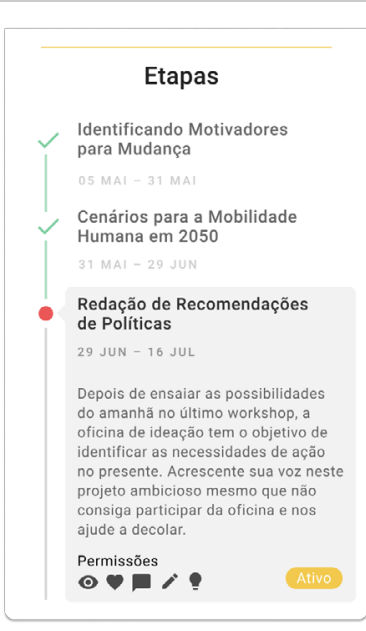

Informações

Compartilhadas do

Entorno e

Geolocalização
Através de uma interface de mapa, é possível demarcar o local de denúncia, ou ainda localizar denúncias realizadas por outros usuários nas proximidades, ou também verificar a localização de obras e contratos públicos para fiscalização. Pode ainda compartilhar outras informações dos usuários no entorno, como a localização de outros usuários, serviços que ofertam, necessidades que possuem, etc.

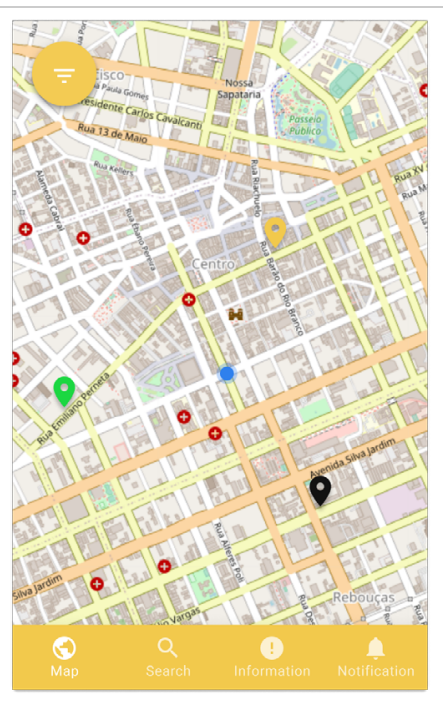

Menu Inteligente

Apresenta como opções de navegação, baseado em seu banco de dados, os itens mais relevantes, a partir das queixas ou sugestões mais recorrentes.

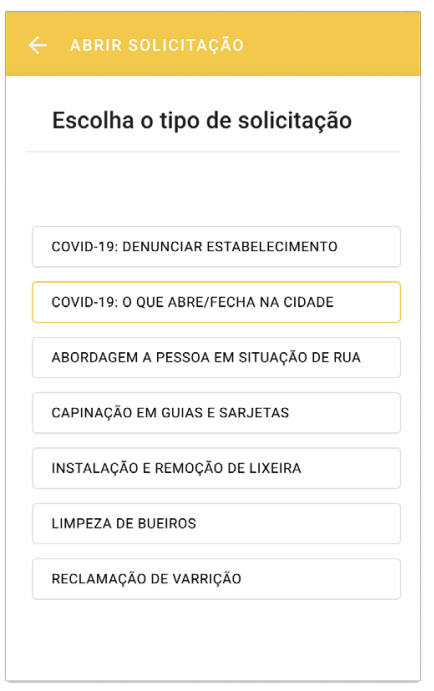


Mural ou

Dashboard

Notificações e Alertas

Proposição
As atividades pessoais, de grupos ou de outros usuários, são dispostas em uma única tela, pode conter também um resumo das atividades do usuário ou do aplicativo como um todo. Compostas por cards contendo informações diversas a respeito do grupo ou da atividade, alinhados verticalmente, um acima do outro, em uma ordem específica, podendo ser clicável, dependendo da feature em que está aplicado, para acessar o grupo, ou possuir botões para reagir ou tomar ações diretamente no mural, ou acessar informações adicionais

O aplicativo, por meio do sistema nativo do celular, encaminha notificações ao usuário a respeito de prazos, novas atividades, novidades no grupo de atividade, ou ainda alertas das autoridades competentes.

Componente com maior complexidade, mas ampla participação ativa, com ela os usuários são capazes de fazer suas propostas, defendê-la com pequenos textos, assim como votar nas propostas de outros usuários, até que se possua o número desejado de propostas. Também pode ser permitida a justificativa dos votos, e ajustado prazos diversos no processo. A seleção pode ser realizada por meio de votações com apenas as opções 'concordo' e 'discordo', ou acrescidas de opções como abstenção ou obstrução, ou ainda com variações como anuência, abstenção e objeção.

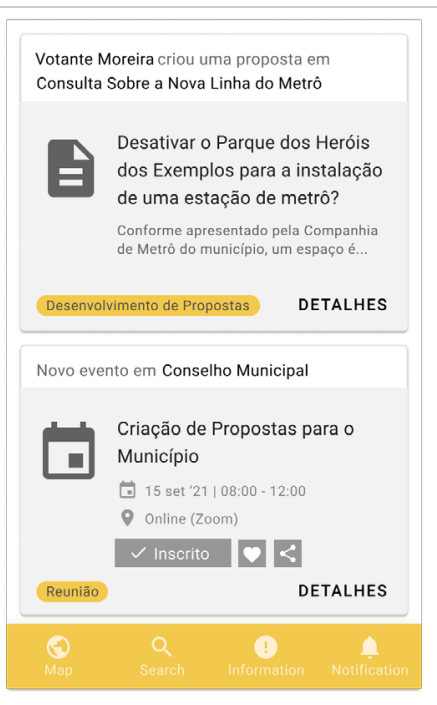

Defesa Civil Informa Alerta de ALAGAMENTO para REBOUCCAS. Evite contato com a água e não fique em áreas baixas. Abra solicitaçăo ou ligue 156 para faze-la.

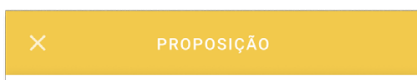

Desativar o Parque dos Heróis dos Exemplos para a instalação de uma estação de metrô?

encerra as 14 h de 18 de jullo de 2021

Conforme apresentado pela Companhia de Metrô do municipio, um espaço é necessário para implantar proponho utilizar o parque que nāo é mais utillizado.

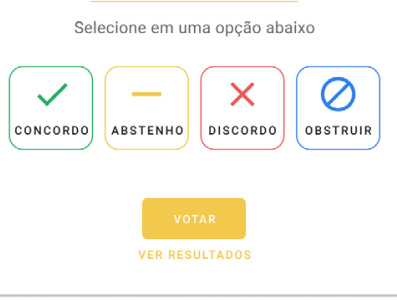

\begin{tabular}{ll} 
Protocolo & $\begin{array}{l}\text { As solicitações, reclamações ou denúncias } \\
\text { são protocoladas no sistema, sendo o usuário } \\
\text { informado com data e hora, cada nova } \\
\text { entrada no processo, sejam elas mudança de } \\
\text { setor, ou de status até a sua conclusão. }\end{array}$ \\
\hline Reconhecimento & $\begin{array}{l}\text { Por meio do uso de IA o aplicativo identifica o } \\
\text { de Imagem }\end{array}$ \\
$\begin{array}{l}\text { contexto da imagem, submetida da memória } \\
\text { câmera, para informar as possiveis } \\
\text { categorias de sua solicitação. }\end{array}$
\end{tabular}

Resposta

O proprietário já foi notificado

Solicitaçăo respondida

Recebida no setor

15/05/2021 08:47

K Reconhecimento de Imagem Tire uma foto ou selecione uma imagem de sua galeria 
Repositório de Documentos
Arquivos importantes como relatórios, resultados dos grupos de discussão, propostas entre outros documentos referente à assuntos internos do aplicativo, são disponibilizados para download em área específica do aplicativo, contendo título, descrição curta e botão para download.

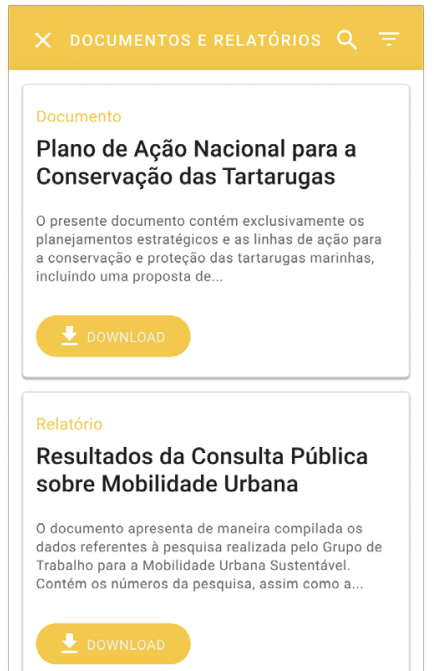

Visão Geral da

Participação
Um painel apresenta de forma compilada em categorias os números referentes a todas as ações do usuário dentro do aplicativo, como tempo investido, ou número de atividades que ele se engajou.

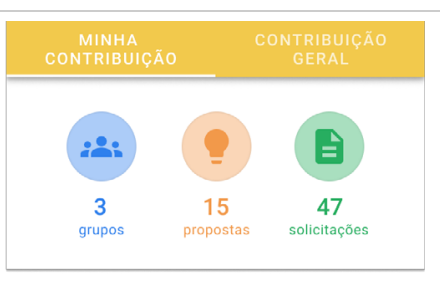

Os componentes podem auxiliar na promoção da protagonização cidadã, da organização civil, formação de grupos de interesse em torno de causas comuns, quando devidamente aplicadas em conjunto com soluções robustas de participação cidadã, potencialmente se tornando uma plataforma para realização de parcerias público-privadas, monitoramento e detecção de problemas e situações de risco, fiscalização, proposição de soluções, e manutenção de ordem pública a partir de uma larga fonte de dados.

\section{Reflexões finais}

Processos participativos, com protagonismo de todas as partes interessadas, são fundamentais para legitimar as decisões políticas para governança pública, promovendo os princípios de inclusão, do pluralismo, igualdade participativa, autonomia, bem comum (Villela et al., 2016). Manzini define cidadãos colaborativos como "grupos de pessoas que colaborativamente resolvem problemas ou abrem novas possibilidades (e que, novamente, tornam-se coprodutores dos resultados obtidos)", e organizações colaborativas como tendo em comum serem "constituídas por grupos de indivíduos que colaboram entre si na co-criação de valores comumente reconhecidos e compartilhados" (Manzini, p. 71)

Esta pesquisa organiza uma biblioteca de componentes digitais para participação e cocriação cidadã ativa, que podem contribuir e facilitar o exercício da cidadania no monitoramento das cidades, assim como de proposição e implementação de soluções, advindas da própria sociedade civil, de grupos de interesse, organização civil, iniciativa privada, fortalecimento de associações, comitês de bairro, integrando, por planejamento estratégico, diversos níveis da sociedade. Processos iterativos, de contínuos feedbacks, próprios de processos de co-criação, 
podem contribuir para melhoria de relações comunitárias, entre grupos, e com autoridades públicas, no ambiente urbano comunitário.

A urbanista Jane Jacobs (2011) afirma que "A troca de ideias, serviços, habilidades e mão de obra, e certamente de produtos, exige transporte e comunicação eficientes, fluentes. (...) As cidades vivas têm uma estupenda capacidade natural de compreender, comunicar, planejar e inventar o que for necessário" (pp. 229, 295). A tecnologia tende a expandir e dinamizar a fluência de comunicação, atendendo aos requisitos democráticos de comunicar com todas as partes envolvidas no contexto de uma causa, e para o estabelecimento de diálogo contínuo entre a administração e cidadãos.

Dados coletados, sobre o estado das cidades, podem ser valiosos para subsidiar a elaboração de políticas públicas, construídas conjuntamente com quem vive a cidade, além da elaboração de indicadores para monitoramento de bem-estar social, como o índice de felicidade interna bruta (FIB-ONU).

No entanto, o ideal e a realidade dos referidos processos em contribuir com a transformação social é impactada pela sua credibilidade em gerar políticas públicas exequíveis e efetivas (Ahimbisibwe et al., 2020), a exemplo da Lei Federal no 10.257/2001 - o Estatuto da Cidade que determina a obrigatoriedade a realização de debates com a participação da população e de associações representativas de segmentos da comunidade, para a elaboração de Planos Diretores. A metodologia de participação requer o próprio design dos processos participativos (Pierre et al., 2021), o design ou escolha de componentes de participação (Afzalan et al., 2017), e diagnóstico da efetividade destas ferramentas em permitir ao usuário expressar sua posição e assim, participar e aprender sobre seu papel social.

O cientista da computação Mumford, um dos teóricos precursores que reconheceu a importância dos processos democráticos de design com participação daqueles para quem se projeta, "viu claramente que o design não pode ser separado da tomada de decisão que ocorre em diferentes estágios de desenvolvimento". Na verdade, sua própria definição de participação é: "um processo no qual duas ou mais partes influenciam uma à outra ao fazer planos, políticas ou decisões. É restrito a decisões que tenham efeitos futuros sobre todos aqueles que tomam as decisões ou sobre aqueles por eles representados" (Mumford, 1983, p. 22 as cited in Olphert \& Damodaran, 2007, p. 494).

Cabe ressaltar que a legislação brasileira em vigor, a Lei Geral de Proteção de Dados Pessoais:

Dispõe sobre o tratamento de dados pessoais, inclusive nos meios digitais, por pessoa natural ou por pessoa jurídica de direito público ou privado, com o objetivo de proteger os direitos fundamentais de liberdade e de privacidade e o livre desenvolvimento da personalidade da pessoa natural (Lei $\mathrm{n}^{\circ}$ 13.709, 2018).

E, portanto, afeta a implementação e os termos de consentimento de uso dos dados do usuário dos aplicativos disponíveis para o cidadão brasileiro. Não esteve no escopo do levantamento realizado neste trabalho, uma análise da existência de features dos aplicativos, ou o estudo de modelos de implementação que garantam o atendimento da referida lei nem o 
uso dos dados coletados. A dimensão ética e a proteção dos direitos fundamentais das pessoas têm sido o foco de estudo na União Européia (European Union [EU], 2021; High-Level Expert Group on Al, 2020).

Futuras pesquisas podem avaliar se aplicativos e o uso dos dados coletados e/ou conectados atendem e suportam os princípios de respeito aos direitos fundamentais do homem e de sua autonomia. Sendo o Brasil um Estado Democrático de Direito, cujas regionalidades possuem autonomia político-administrativa, a biblioteca de ferramentas poderá auxiliar na zeladoria de interesses locais, valorizando e preservando regionalidades, cultura e patrimônio, de forma democrática e igualitária, e para um desenvolvimento global sustentável.

\section{Referências}

Afzalan, N., Sanchez, T. W., \& Evans-Cowley, J. (2017). Creating smarter cities: Considerations for selecting online participatory tools. Cities, 67, 21-30. https://doi.org/10.1016/j.cities. 2017.04.002.

Ahimbisibwe, K. F., Ndidde, A. N., \& Kontinen T. (2020). Participatory methodology in exploring citizenship: A critical learning process. Routledge Explorations in Development Studies. Holma, K. \& Kontinen, T (Ed.). 159-175. https://library.oapen.org/bitstream/handle/20.500. 12657/41700/9781000732207.pdf?sequence=1\#page=172

Arstein, S. R. (1969). A Ladder Of Citizen Participation. Journal of the American Institute of Planners. 35, 216-224. http://dx.doi.org/10.1080/01944366908977225

Brasil. (2018, nov. 16). The people in power: understand how citizens participate directly in a democracy. Brazil Gov News. http://www.brazil.gov.br/about-brazil/news/2018/11/thepeople-in-power-understand-how-citizens-participate-directly-in-a-democracy

Capacidades. (n.d.). O Programa: Referências Gerais. http://www.capacidades.gov.br/pg/oprograma/referenciasgerais

Centro Regional de Estudos para o Desenvolvimento da Sociedade da Informação. (2021). Pesquisa web sobre o uso da Internet no Brasil durante a pandemia do novo coronavírus: Painel TIC COVID-19. (livro eletrônico) . Núcleo de Informação e Coordenação do Ponto BR (Ed.). 1. ed. São Paulo: Comitê Gestor da Internet no Brasil https://cetic.br/media/docs/ publicacoes/2/20210426095323/painel_tic_covid19_livro_eletronico.pdf

Dialoga Brasil. (n.d.). Sobre. http://dialoga.gov.br/sobre

European Union. (2021). Coordinated Plan On Artificial Intelligence 2021 Review. Brussels: European Commission. https://digital-strategy.ec.europa.eu/en/library/coordinated-planartificial-intelligence-2021-review

Freire, T. (2020, abr. 29). IBGE: Um a cada quatro brasileiros não tem acesso à Internet. Radioagência Nacional. https://agenciabrasil.ebc.com.br/radioagencianacional/geral/audio/2020-04/ibge-um-cada-quatro-brasileiros-nao-tem-acesso-internet

Garrett, J. J. (2010). The elements of user experience: user-centered design for the web and beyond. London: Pearson Education. 
Gaudio, C. (2019). Design participativo e inovação social: a influência dos fatores contextuais [Tese de Doutorado]. Departamento de Artes \& Design. Pontifícia Universidade Católica do Rio de Janeiro, Rio de Janeiro. https://doi.org/10.17771/PUCRio.acad.37115

High-Level Expert Group on Al. (2020). The assessment list for trustworthy artificial intelligence (ALTAI) for self assessment. Brussels: European Commission. https://doi.org/10.2759/002360

Instituto Brasileiro de Geografia e Estatística. (2021). Acesso à internet e à televisão e posse de telefone móvel celular para uso pessoal 2019. https://biblioteca.ibge.gov.br/ visualizacao/livros/liv101794_informativo.pdf

Jacobs, J. (2011). Morte e vida de grandes cidades. São Paulo: WMF Martins Fontes. 3. ed.

Lei $n^{\circ} 13.709$, de 14 de agosto de 2018 do Congresso Nacional. (2018). Diário Oficial da União: edição 157, seção 1, p. 59. https://www.in.gov.br/web/dou/-/lei-no-13-709-de-14-de-agostode-2018-36849337

Lei $n^{\circ}$ 14.129, de 29 de março de 2021 do Congresso Nacional. (2021). Diário Oficial da União: edição 60, seção 1, p. 3. https://www.in.gov.br/en/web/dou/-/lei-n-14.129-de-29-de-marcode-2021-311282132

Manzini, E. Design para a inovação social e sustentabilidade: Comunidades criativas, organizações colaborativas e novas redes projetuais. Rio de Janeiro: E-Papers.

Ministério do Desenvolvimento Regional. (2020). Ouvidoria. https://www.gov.br/mdr/ptbr/canais_atendimento/ouvidoria

Muller, M. J. \& Kunn, S. (1993). Participatory Design. Communications of the ACM, 36, 4, 25 28. https://doi-org/10.1145/153571.255960

Nielsen, J., Loranger, H. Prioritizing web usability. New York: New Riders, 2006.

Organisation for Economic Co-operation and Development. (2001). Citizens as Partners: Information, Consultation and Public Participation in Policy-Making. Paris: OECD.

Olphert, W., \& Damodaran, L. (2007). Citizen Participation and engagement in the Design of eGovernment Services: The Missing Link in Effective ICT Design and Delivery. Journal of the Association for Information Systems (JAIS), 8, IX, 491-507. https://aisel.aisnet.org/cgi/ viewcontent.cgi?article $=1327 \&$ context=jais

Pierre, J., Crooks, R., Currie, M., Paris, B., \& Pasquetto, I. (2021). Getting Ourselves Together: Data-centered participatory design research \& epistemic burden. Proceedings of the 2021 CHI Conference on Human Factors in Computing Systems (CHI '21), 406, 1-11. https://doi.org/10.1145/3411764.3445103

Secretaria Municipal de Desenvolvimento Urbano. (2018). Guia Metodológico dos Processos Participativos. https://gestaourbana.prefeitura.sp.gov.br/wp-content/uploads/2018/02/GuiaMetodológico-de-Participação.pdf

Vilella, L. E., Vidal, M. O., Araujo, A. C., Costa, N. L. S. F., \& Costa, E. G. (2016). A conferência nacional das cidades como instrumento de políticas públicas para o desenvolvimento territorial: a percepção dos conselheiros nos processos participativos e deliberativos. Cadernos EBAPE.BR, 14, 619-639. https://doi.org/10.1590/1679-395117094 